\title{
Assessment of work related musculoskeletal pain among professional drivers in the service of a tertiary institution
}

\author{
Ojoawo Adesola Ojo*, Onaade Oluwaseun, Adedoyin Rufus, Okonji Adaobi \\ Department of Medical Rehabilitation, Faculty of Health Sciences, ObafemiAwolowo University, Ile Ife, Osun State, Nigeria
}

Email address:

aoojoawo@yahoo.com (Ojoawo A. O.)

\section{To cite this article:}

Ojoawo Adesola Ojo, Onaade Oluwaseun, Adedoyin Rufus, Okonji Adaobi. Assessment of Work Related Musculoskeletal Pain among Professional Drivers in the Service of a Tertiary Institution. American Journal of Health Research. Special Issue: Supplementary Prescribing in Nigeria: A Needy Concept to Promote Clinical Physiotherapy Practice. Vol. 2, No. 5-1, 2014, pp. 56-60.

doi: $10.11648 /$ j.ajhr.s.2014020501.21

\begin{abstract}
Musculoskeletal pain (MSP) is usually work related and it is a common phenomenon among several occupations. This study aimed at determining the prevalence and pattern of work related musculoskeletal pain (WRMSP) among drivers at a Nigerian tertiary institution. An adapted Nordic musculoskeletal pain questionnaire (NMSPQ,) was distributed to all the professional drivers who were staff of Obafemi Awolowo University, Ile Ife, Osun State, Nigeria. The response rate was 90.9\%. The data were analyzed using descriptive and inferential statistics. The result showed that $77 \%$ of the professional drivers (PDs) reported WRMSP once or more in their routine duties. Low back $(50.5 \%)$ was the most frequently sited location of WRMSP while shoulder $(35 \%)$, knees $(30.9 \%)$, neck $(26.8 \%)$, ankle $(26 \%)$, elbow; and hip $(22.7 \%)$ were other regions. Prolonged driving was reported to be a major cause of musculoskeletal pain $(61.2 \%)$. There was significant relationship between musculoskeletal pain intensity and duration of driving per week $(r=0.348, p<0.05)$ and absenteeism from work $(r=0.356$, $\mathrm{p}<0.05)$. The study concluded that MSP was prevalent among drivers at the selected institution and low back was the most predisposed site.
\end{abstract}

Keywords: Musculoskeletal Pain, Drivers, Nordic Questionnaires, Low Back Pain, Shoulder Pain

\section{Introduction}

Musculoskeletal pain affects all ages, re-occur most times, and the frequency increases with age. A higher percentage of most adults might have experienced one or more brief episodes of musculoskeletal pain which are usually associated with injury or overuse [1]. Musculoskeletal pain is a major health problem that affects quality of life, causing morbidity, increase in demand for health care and cost $[2,3]$. Chronic musculoskeletal pain, often in association with rheumatic disease, is a major cause of disability [2]. Health problems range from discomfort, minor aches, and pains, to more serious medical conditions requiring time off work and even medical treatment. In more chronic cases, treatment and recovery are often unsatisfactory, and the effects could be permanent disability and loss of employment [4]. Workrelated musculoskeletal pain (WMSP) is defined as musculoskeletal disorders that results from a work-related event [5]. Work-related musculoskeletal pain can affect almost all parts of the body especially the back, neck and upper limbs, depending upon the physical movement characteristics, and the ergonomic and mechanical design of work tasks [6]

Majority of occupations in which individuals are engaged all over the world, are associated with a high risk of developing injury [7]. Musculoskeletal disorders are among the most prevalent [7] and the most frequently reported work related disease. It accounted for 34 percent of all workplace injuries and illnesses requiring absenteeism from work in 2012 at the United States [8]. Many musculoskeletal pain problems are highly prevalent; and the economic implications of musculoskeletal pain are enormous. Aside unemployment, compensation paid to persons unable to work due to musculoskeletal pain (in the United States); painrelated lost productivity among employed persons is extremely common and costly [9]. Porter et al and Magnisson et al. documented the prevalence and risk of developing musculoskeletal troubles among car drivers in the UK $[10,11]$. In Nigeria, the pattern of musculoskeletal pain in selected occupation (auto-mechanics, typist and secretaries, fashion designers and market traders) and prevalence among timber 
workers in Enugu metropolis, Nigeria had been documented $[12,13]$. Similar documentation had been made on, the prevalence of musculoskeletal injuries among factory workers in Kano Metropolis, Nigeria [14]. Akinbo et al also reported characteristics of back pain among commercial drivers and motorcyclists in Lagos while Akinpelu et al reported prevalence of musculoskeletal pain and health seeking behaviour among occupational drivers in Ibadan, Oyo state, Nigeria $[15,16]$. There were also undocumented reports of various musculoskeletal pains in Obafemi Awolowo University (OAU) Teaching Hospitals from drivers. However, the pains were not attributed to any cause while prevalence was also not established. This study was designed to investigate the prevalence of MSP among professional drivers at OAU Ile Ife

\section{Material and Method}

\subsection{Participants}

Participants in this study were professional drivers who were staffs of Obafemi Awolowo University, Ile-Ife, Osun State, Nigeria.

\subsection{Inclusion and Exclusion Criteria}

The major inclusive criterion was that there should be no history of traumatic episode in the last 12 months prior to this study among participants. Other drivers who were employed individually by staff members were excluded from the study.

\subsection{Sample Size}

All drivers (110) duly employed for the services of the university were recruited for the study.

\subsection{Instrument}

The survey instrument was the adapted Nordic questionnaire [17]. This is a standardized questionnaire that took cognizance of musculoskeletal pain affecting nine body sites namely: neck, shoulder, upper back, elbows, low back, wrist/hand, hip/thigh, knees and ankles/feet. The questionnaire obtained information on musculoskeletal pain such as aetiology, incidence of pain, intensity of pain, duration of injury, body parts affected and information on sick leave due to musculoskeletal pain. A new section was structured to assess socio demographic information of the respondent (age, sex, academic qualification, marital status, year of driving experience, type of vehicle and average period spent in each driving session). A pilot study was conducted on 5 drivers to assure the understanding and clarity of the questionnaire. Based on the results of the pilot study, linguistic modification of some questions was made to avoid confusion and make interpretation easy (without alteration in the original meaning).

\subsection{Procedure}

Ethical approval (IPHOAU/12/152) was granted by the
Health Research and Ethics Committee, Institute of Public Health, ObafemiAwolowo University, Ile Ife. Similarly, written permission was obtained from the chief drivers' office and each driver consented to participate in the study. The copies of questionnaire were distributed by the main investigator, and on completion, they were collected immediately. The participants were assured of confidentiality of information given.

\subsection{Data Analysis}

Statistical Package for Social Sciences (SPSS) software version 16 was used to analyse the data. Descriptive statistics of mean, standard deviation and frequency were used to summarize data. Inferential statistics of Spearman Rho correlation analysis was used to test the relationship between musculoskeletal pain intensity; and years of experience, types of automobile being driven, frequency of driving per week, and number of hours driving. Alpha level was set at $\mathrm{p}<0.05$.

\section{Result}

A total of 110 copies of questionnaire were distributed but 100 were found to be valid for analysis and this represented a response rate of $90.9 \%$. Presented in table 1 is the sociodemographic data of respondents. The mean age was $44.8 \pm$ 11.1years, more than average had secondary education $(54.0 \%)$ and a larger percentage (91\%) were married. Table 2 showed the distribution of respondent based on years of experience in driving, types of vehicle and number of hours spent in active driving per week.

Table 1. Socio demographic characteristics of respondents $(N=100)$

\begin{tabular}{lll}
\hline Parameters & Frequency & Frequency (\%) \\
\hline Age & 21 & \\
Min & 60 & - \\
Max & & - \\
Qualification & 5 & 5.0 \\
Nil education & 26 & 26.0 \\
Primary & 54 & 54.0 \\
Secondary & 15 & 15.0 \\
Tertiary & & \\
Marital Status & 91 & 91.0 \\
Married & 9 & 9.0 \\
Single &
\end{tabular}

Table 2. Occupational characteristics of respondents

\begin{tabular}{lll}
\hline Parameters & $\mathbf{N}$ & $\mathbf{\%}$ \\
\hline $\begin{array}{l}\text { Driving experience } \\
\leq 10 \text { Years }\end{array}$ & 49 & 49.0 \\
11- 20 Years & 13 & 13.0 \\
$\geq 20$ Years & 38 & 38.0 \\
Type of Vehicles & & \\
Car & 44 & 44.0 \\
Bus & 29 & 29.0 \\
Truck & 12 & 12.0 \\
All Vehicle & 15 & 15.0 \\
Driving per week & & \\
$\leq 5$ Hours & 13 & 13.0 \\
6-10hrs & 22 & 22.0 \\
$>10$ hours & 65 & 65.0 \\
\hline
\end{tabular}


Presented in tables 3 and 4 are the summaries of the effects and prevalence of WMSP. A total of 77 respondents (77.0\%) have had musculoskeletal pain and $49.3 \%$ have been absent from work at one time or the other due to pain. The commonest site of pain in the last 12 months was low back pain $(63.3 \%)$ followed by the shoulder $(35 \%)$ and the least was the upper back (14.4\%). In the lower limb, the commonest site of pain was the hip (25.0\%), closely followed by the ankle (21.1\%).

Table 3. Effects of Work Related Musculoskeletal Pain on routine activity

\begin{tabular}{lll}
\hline Variables & Yes (N/\%) & No (N/\%) \\
\hline WRMSP & $77(77.0)$ & $23(23.0)$ \\
Prevented from driving & $24(31.2)$ & $52(69.8)$ \\
Related to absenteeism & $38(49.3)$ & $39(50.6)$ \\
\hline
\end{tabular}

Key: WRMSP=Work Related Musculoskeletal Pain

Table 4. Prevalence of WMSP in the last 12 months and 7 days

\begin{tabular}{lll}
\hline Affected sites & Last 12 month N (\%) & Last 7 days N (\%) \\
\hline Neck & $26(33.7)$ & $9(11.7)$ \\
Shoulder & $34(44.1)$ & $12(15.6)$ \\
Elbow & $22(28.6)$ & $7(9.1)$ \\
Wrist & $28(36.4)$ & $8(10.4)$ \\
Upper Back & $14(18.2)$ & $3(3.8)$ \\
Lower Back & $49(63.6)$ & $20(26.0)$ \\
Hip & $22(28.6)$ & $13(16.8)$ \\
Knee & $30(38.9)$ & $13(16.8)$ \\
Ankle & $25(32.4)$ & $11(14.3)$ \\
\hline
\end{tabular}

Presented in table 5 is the prevalence of musculoskeletal pain according to the types of vehicle. There were $32 \%$ drivers with MSP pain among the car drivers. Among drivers of buses, $29 \%$ had pain while $11 \%$ of those drivers driving all types of vehicle had pain.

Table 5. Prevalence of Musculoskeletal Pain according to types of vehicle $N=100$

\begin{tabular}{llll}
\hline Types & N & Pain (\%) & Nil pain \\
\hline Cars & 44 & $32(32)$ & 12 \\
Trucks & 12 & $10(10)$ & 2 \\
Buses & 29 & $24(24)$ & 5 \\
All & 15 & $11(11)$ & 4 \\
Total & 100 & $77(77)$ & 23 \\
\hline
\end{tabular}

Table 6. Percentage distribution of respondent based on incidence of pain

\begin{tabular}{lll}
\hline & N & \% \\
\hline Mode of onset & 56 & 72.7 \\
Gradual & 21 & 27.3 \\
Sudden & 77 & 100 \\
Total & & \\
Pain duration & 54 & 70.1 \\
Days & 12 & 15.6 \\
Weeks & 10 & 13.0 \\
Months & 1 & 1.3 \\
Years & & \\
Nature of Pain & 65 & 76.5 \\
Intermittent & 12 & 23.5 \\
Continuous & 77 & 100 \\
Total & & \\
Activities & 40 & 51.9 \\
Prolong Sitting & 30 & 38.9 \\
Prolong Standing & 7 & 9.1 \\
Others &
\end{tabular}

Table 6 shows the frequency, mode of onset, duration and nature of pain of respondents. With respect to those that had experienced pain, fifty six respondents $(72.7 \%)$ reported that the pain started gradually while twenty one respondents $(27.3 \%)$ reported that it was a sudden onset of pain while prolong sitting and standing were the major activities of the respondents.

Table 7 presents the summary of Spearman's Rank correlation analysis showing the relationship between musculoskeletal pain intensity and years of experience, types of vehicle, hours of driving and work absenteeism. The study showed significant relationship between musculoskeletal pain intensity and number of hours spent in driving $(r=0.35$, $\mathrm{p}<0.05)$ and also between musculoskeletal pain intensity and absenteeism from work $(\mathrm{r}=0.36, \mathrm{p}<0.05)$.

Table 7. Relationship between pain intensity and absenteeism from work, driving experience, type of vehicle and driving parameters

\begin{tabular}{|c|c|c|c|c|c|c|}
\hline Variable & Pain & Experience & Vehicle & Hours/wk & Leave & drive/wk \\
\hline Pain & 1 & & & & & \\
\hline Experience & 0.104 & 1 & & & & \\
\hline Vehicle & 0.084 & 0.119 & 1 & & & \\
\hline Hours/wk & $0.348 *$ & 0.079 & -0.230 & 1 & & \\
\hline Leave & $0.356^{*}$ & -0.060 & 0.016 & -0.110 & 1 & \\
\hline Drive/ wk & -0.083 & 0.151 & 0.056 & 0.0430 & $0.259 *$ & 1 \\
\hline
\end{tabular}

Key: * Significant at $\mathrm{p}<0.05$. Pain $=$ Pain Intensity, $w k=$ week.

\section{Discussion}

We observed a prevalence rate of $77.0 \%$ of musculoskeletal pain among occupational drivers in the university community. This was higher when compared to $50 \%$ reported for professional drivers by Magnusson et al, among commercial vehicle drivers in Peninsular Malaysia [11] but lower than that of Akinpelu et al [16] who reported 89.3\% prevalence among occupational drivers in Ibadan, Nigeria. The most prevalent body site was low back in the last 12 months. Previous studies have documented various rates of work-related low back pain in drivers of various populations for a 12-month time period. Jiu et al, reported $51 \%$ low back pain prevalence among urban taxi drivers at Taipei City, Taiwan while Andrusaitis et al, reported 59\% prevalence among truck drivers in Sao Paulo, Brazil $[18,19]$. Similarly, Najenson et al reported $45 \%$ prevalence among professional bus drivers in Israel [20]. Akinpelu et al reported $64.8 \%$ on prevalence of low back pain among occupational drivers at Ibadan, Nigeria [16]. Akinbo et al also reported $64.5 \%$ prevalence of back pain among commercial motor drivers in Lagos, Nigeria among which he reported $59.3 \%$ of low back pain prevalence [15]. Tamrin et al reported $60.4 \%$ prevalence of low back pain among commercial vehicle drivers in Peninsular Malaysia [21]. These reports showed that professional drivers are at higher risk for low back pain and various spinal disorders [18].

Odebiyi et al, however, reported a higher 12-month prevalence rate of $96 \%$ and $88 \%$ for LBP among the commercial motor drivers and private automobile/drivers respectively in Lagos [22]. Low back pain had been 
identified as one of the most costly disorder in the worldwide population, and activities such as sitting, whole body vibration and awkward postures have been associated with the risk of developing low back pain [23]. Also uncomfortable seat, back support and gear level were observed to be associated with a higher prevalence of LBP [20,24]. Studies showed that some types of car seats contributed to the development of LBP, particularly, in people who drive for long hours $[25,26,27]$. The car seat pan and its backrest usually keeps the driver's hip in an angle $90^{\circ}$ or less, thus predisposing the lower lumbar discs to a greater pressure; the resultant forces subsequently contributes to injury of the LB and degeneration of the lumbar spine [27]. Loss of rigidity or sagging of the car seat (usually due to wear and tear) has also been suggested to predispose the low back to injury, and it has been established that this causes the knees to be elevated higher than the pelvis [26,27]. This might result in the concentration of the gravitational forces of the upper part of the body at the lower lumbar spine [27]

Other musculoskeletal pain reported after low back pain was shoulder pain $(35 \%)$ followed by knee $(30 \%)$, the least site of pain is the upper back (14.4\%). Backman reported an increased incidence of shoulder and back pain among professional drivers [28]. Akinpelu et al reported 30.8\% and $27 \%$ for prevalence of shoulder and knee pain respectively among drivers in Ibadan, Nigeria [16] while Tamrin et al reported $35.4 \%$ and $29.3 \%$ for shoulder and knee pain respectively [21].

It was observed in this study that the number of hours spent in driving per week was significantly related to pain intensity, an indication that hours spent in driving and years of experience may influence development musculoskeletal. This result corroborated that of Porter et al and Pietri et al, that increased time of driving was a major risk factor in development of musculoskeletal pain among drivers [29,30]. Also, Sadri reported that neck pain was more prevalent among bus drivers with long driving hours than with short driving hours [24]. This was probably due to prolonged sitting, whole body vibration, awkward posture while driving such as slumped sitting, leaning on one side, bending and twisting; excessive reaching and restricted movement [23,29, 31]. Prolonged sitting behind the wheel can cause significant postural strains on back muscles and the lumbar spine [32, 33]. Chen et al found that driving a car or van for 4 hours/day was associated with a high prevalence of LBP [29]. Porter et al, also found that driving 20 hours/week was associated with high frequency of low back trouble and related sickness [33]. These were in tandem with our findings.

We found significant relationship between musculoskeletal pain intensity and absenteeism from work. This is consistent with Porter et al who reported sickness absence due to low back trouble among car drivers in the UK [29]. Also, statistics from bureau of labour department in the United States reported heavy and tractor-trailer truck drivers as having the highest median days away from work compared with other workers in their group [8]. We found no significantly association between pain intensity and years of driving experience. This corroborated finding of Sadri who reported no significant relationship between bus drivers experiencing back pain and job experience. Contrarily, Nicole reported that years of driving significantly influenced low back pain experience. Akinpelu et al, also reported that the prevalence of musculoskeletal pain was found to be higher with longer years of driving experience [16, 24, 34]. We attributed the in-significant relationship between years of experience and pain intensity to the acquisition of knowledge about injury prevention during driving period. The experienced drivers might be able to adopt preventive strategies for musculoskeletal problems than the less experienced ones. Survivor effect could also be another factor. Healthy survivor effect describes a continuing selection process such that those who remain in an employment tend to be healthier than those who leave [35]. The healthy worker survivor effect generally reduces an adverse effect of exposure [35]. Najenson et al and Tinubu et al also documented the influence of survivor effect or healthy worker effect in their study on back pain among professional drivers and bus drivers in Israeli and among Nurses in Ibadan, Nigeria respectively $[5,20]$.

We found no significant association between types of vehicle and pain intensity among respondent of the study which was in contrary to the report of Porter et al, who documented a significant association between type of vehicle and prevalence of musculoskeletal pain [29]. Among factors that can lead to development of musculoskeletal pain with respect to types of vehicle were variation with seat comfortability, steering wheel adjustability and position, type of gear box, head space, cruise control, back rest angle adjustment, pedal position [21, 29,31]. Our study did not assess these factors; hence, they might be limitations of this study. The result in this study might probably be due to drivers adapting to various postures (e.g. sitting straight or leaning) to reduce pain experience [29]. For instance some drivers might have unknowingly compensated for a lack of headroom by reclining the seats back more than they normally would for comfort $[21,22]$. More so, university community is a source of knowledge, drivers in the system might have learnt the proper sitting posture and adjustment of vehicles' seat during the course of their work.

\section{Conclusion}

This study concluded that musculoskeletal pain was prevalent among occupational drivers in the sampled Nigerian tertiary institution. The most common site of pain was the low back and this often resulted into absenteeism from work.

\section{References}

[1] Kvien TK, Mikkelsen K, Nordvag. Core Curriculum for Professional Education in Pain. (J. E. Charlton, Ed.).J Rheumatol 2003; 30:1135-1137. 
[2] Reginster JY, Khaltaev NG. Introduction and WHO perspective on the global burden of musculoskeletal conditions. Rheumatology 2002; 41(Suppl 1):1-2.

[3] Woolf AD, Pfleger B. Burden of major musculoskeletal conditions. World Health organization2003.

[4] Magdy A. Darwish and Shatha Z. Al-Zuhair: Musculoskeletal Pain Disorders among Secondary School Saudi Female Teachers. Volume 2013; Article ID 878570,7 pgs.

[5] Tinubu Bolanle MS Tinubu Chidozie E Mbada Adewale L Oyeyemi Ayodele A Fabunmi. Work-Related Musculoskeletal Disorders among Nurses in Ibadan, South-west Nigeria: a cross-sectional survey.BMC Musculoskeletal Disorders 2010; $11: 12$.

[6] Chyuan J.A, Du C, Yeh W, Li C. Musculoskeletal disorders in hotel restaurant workers. Occup Med 2004; 54:55-57

[7] Buckwalter, JA., Woo, SLY., Goldberg, VM, Hadley, EC, Booth, F. and Oegema, TR. Current concepts review: Soft tissue aging and musculoskeletal function. Journal of Bone and Joint Surgery 1993; 75(10), 1533- 1548.

[8] BLS (Bureau of Labour Statistics of the U.S department of labour). Non-fatal occupational injuries and illnesses requiring days away from work. USDL 2012;13-2257.

[9] IASP (International Association of the Study of Pain). Global year of musculoskeletal pain 2009

[10] Pope MH, Goh KL, Magnusson ML. Spine ergonomics. Industrial Health 2002;45, 268-278.

[11] Magnusson ML, Pope MH, Goh KL. Spine ergonomics. Industrial Health 2002; 45, 268-278.

[12] Olaogun MOB. Pattern of musculoskeletal pain in selected occupation.Journal of Nigeria association of physiotherapy 2002; Vol. 14.No. 1. (2002), Vol. 14. No. 1.

[13] Ezeukwu, Ugwuoke Jeneviv, Egwuonwu, Abaraogu. Prevalence of work-related musculoskeletal pain among timber workers in enugu metropolis, nigeria. Continental J. Tropical Medicine 2011; 5 (2) 11 - 18.

[14] Ismaila, Victor, Adeolu. International Journal of Occupational Safety and Ergonomics 2011; Vol. 17, No. 1 (No. 1), 99-102.

[15] Akinbo S R, Odebiyi DO, Osasan A A . Characteristics of back pain among commercial drivers and motorcyclists in Lagos, Nigeria. West Afr J Med.2008; 27(2), 87-91.

[16] Akinpelu AO. Oyewole OO. Odole AC and Olukoya RO. Prevalence of Musculoskeletal Pain and Health seeking Behaviour among Occupational Drivers in Ibadan, Nigeria .Afr. J. Biomed. Res.2011; 14, 89 - 94.

[17] Kuorinka IJB. Standardised Nordic questionnaire for analysis of musculoskeletal symptoms. Applied E r p nomirs 1987; $18: 233-237$

[18] Jiu-Chiuan Chen, C. W. Occupational factors associated with low back pain in urban taxi drivers. Occup Med 2005; 55(7), 535-540.
[19] Andrusaitis SF, Oliveira RP, Filho TEPB. Study of the prevalence and risk factors for low back pain in truck drivers in the state of São Paulo, Brazil.Clinics. 2006 Dec;61(6): 50310.61(6).

[20] Najenson-Deborah Alperovitch, YSL. Low Back Pain among Professional Bus drivers: ergonomic and OccupationalPsychosocial risk Factors. IMAJ 2010; VOL 12.

[21] Tamrin SBM. The association between risk factors and low back pain among commercial vehicle drivers in peninsular Malaysia: a preliminary report. Industrial Health 2007; 45:268-278.

[22] Odebiyi DO, DC Ogwezi, BOA Adegoke. The prevalence of low back pain in commercial motordrivers and private automobile drivers. Nigerian Journal of Medical Rehabilitation2007; Vol. 12, No.1 \& 2, (Issue No. 20)

[23] Angela Maria, Katie M. Association between sitting and occupational low back pain. Eur spine J 2007 ;16(2);283-298

[24] Sadri Gholam-Hossain. Risk factors of musculoskeletal disorders in bus drivers. Arch Iranian Med 2003; 6 (3): 214 215.

[25] McKenzie R. The Lumbar Spine, Mechanical Diagnosis and Therapy. Waiknae: Spinal Publications 1990.

[26] Boshuizen HC, Bongers PM, Hulshof CT. Self-reported back pain in tractor drivers exposed to whole body vibration. Int Arch Occup Environ Health 1990; 62(2): 109

[27] Hedge A. Dr'iving and Low Back Pain. Americall JOlll'11al of Rehabilitative Medicille2002;57(1): 26 -34.

[28] Backman A. Health survey of professional drivers. Scand J Work Environ Health1983; 9, 30 - 5.

[29] Porter JM, GyiDE .The prevalence of musculoskeletal troubles among car drivers. Occup. Med 2002.Vol. 52. No 1, pp. $4-12$

[30] Pietri F, Le Clerk A, Bottel L, Chastang J.F, Morcet J.F, Blondet M. Low back pain in commercial travelers. Scandinavian Journal of Work and Ergonomental Health1992; 18: 5

[31] Deborah -Najenson Alperovitch YSL. low Back Pain among Professional Bus drivers: ergonomic and OccupationalPsychosocial risk Factors. IMAJ 2010; VOL 12.

[32] Johnson DA, Neve M. Analysis of possible lower lumbar strains caused by the structural properties of automobile seats: a review of some recent technical literature. J Manipulative Physiol Ther 2001; 24: 582-588

[33] Chen Jiu-Chiuan, WC. Occupational factors associated with low back pain in urban taxi drivers. Occup Med 2005; 55(7), 535-540.

[34] Nicole M. Bus driver's health and condition of work. Paper presented at the ECOHSE 2000 symposium, Lithuania:4-7

[35] Arrighi HM, Hertz-Picciotto I. The evolving concept of the healthy worker survivor effect. Epidemiology. 1994; 5(2), 189-196. 